\title{
The P/B-Method, About 50 Years a Hidden Champion
}

\author{
F. Eggert $^{1}$
}

${ }^{1 .}$ EDAX Inc., Ametek Materials Analysis Division, 91 McKee Drive, Mahwah, NJ.

The basis of the $\mathrm{P} / \mathrm{B}$ quantification method is the evaluation of the measured characteristic X-ray counts in relation to measured bremsstrahlung continuum and EDS has opened the opportunity to measure both at the same time. It began 50 years ago with the application for biological samples in TEM by Hall [1] and was applied for the first time for SEM about 40 years ago by three authors/groups at the same time [2-4]. But each did his research and publication with quite different base motivation. Small [3] was focussed to application with particle analysis and Statham to rough bulk samples surfaces [4], while Wendt [2] has pointed out in his abstract the benefits with $\mathrm{P} / \mathrm{B}$ for "more accurate results" for standardless analysis application with flat bulk samples. The advantages with $\mathrm{P} / \mathrm{B}$ method for general application with bulk samples are quickly summarized. First at all, the measured $\mathrm{P} / \mathrm{B}$ values depend almost linear from element concentration, a base differentiator to all net-count measurement-based methods. This means, the matrix corrections due to different sample compositions are comparably small. The physical models-based matrix correction is the biggest influence factor to result-accuracy with all standardless analysis. If small corrections are applied with the model, then the model mistakes and all uncertainties in the used model formula and atomic data are suppressed in regards of influence to the calculated analytical results, the element composition. The second base advantage of a P/B-method is that the base algorithm does not need result normalization [5]. This means, the results are determined for each individual element in an absolute way and should be in the 'ideal case' total about $100 \%$, if all individual results will be added. The most important atomic parameters with $\mathrm{P} / \mathrm{B}$ models are the cross sections of electron shells, even the ratio of characteristic lines excitation to bremsstrahlung cross sections with (usually) the same electron energy. But these fundamental parameters are even possible to determine (adjust) with the model itself. Therefore, no big database is really required to get good accuracy with a P/B model for standardless analysis of completely unknown samples. The benefits with low dependence of sample surface conditions and even usability for particles is 'only' an additional effect. Any geometry effect or sample charging issue in daily routine data acquisition has about one order of magnitude less influence on the results. The advantage with base accuracy is the reason the P/B method is still alive and available to use with several commercial systems; it became a standardless EDS work horse.

One should not conceal the disadvantages. The measured $\mathrm{P} / \mathrm{B}$ value has a higher statistical uncertainty than net-counts. This requires more counts, meaning longer acquisition times until the precision of the $\mathrm{P} / \mathrm{B}$ for major sample elements is practically similar to the net-counts. However. this limitation was reduced over the years with the development of SDD detectors with high count-rate abilities. Nevertheless, the $\mathrm{P} / \mathrm{B}$ method is not the method of choice for comparison measurements, to investigate concentration variations, if the precision is the major focus.

It needs to be mentioned that the $\mathrm{P} / \mathrm{B}$ method fails for characteristic line energies below $1 \mathrm{keV}$ (therefore for elements with atomic number below 11 it is required to use an internal hybrid approach with conventional ZAF notation) and is not adaptable to 'low-kV applications'. It is recommended to use with an SEM high-voltage excitation $\geq 10 \mathrm{kV}$. 
Publications about P/B methods never dried up over the decades [5-8]. Due to the 'absolute' notation of a $\mathrm{P} / \mathrm{B}$ algorithm, this is even applicable for full EDS spectra simulation [8].

A recently investigation in regard to standardless result accuracy (after a base model revision and improvement) was with quite brilliant results for a pure fundamental parameter standardless analysis. With a measured standard deviation of $5-7 \%$, other methods than $\mathrm{P} / \mathrm{B}$ are not able to achieve without using an additional database which includes empirical measurements (remote-standards).

\section{References:}

[1] T.A. Hall, Nat. Bur. Stand. Spec. Publ. 298 (1968), p. 298.

[2] M. Wendt, Kristall und Technik 13 (1978), p. 1259.

[3] J.A.Small et al, Nat. Bur. Stand. Spec.Publ. 533 (1978), p. 29.

[4] P.J.Statham, Microchim. Acta, Suppl. 8 (1979), p. 229.

[5] J.Heckel, P.Jugelt, X-Ray Spectrometry 13 (1984), p. 159.

[6] F.Eggert, J.Heckel, Experim. Techn. d. Physik 34 (1986), p. 201.

[7] J.Trincavelli, R. Van Grieken, X-Ray Spectrometry 23 (1994), p. 254.

[8] F.Eggert, Microchim Acta 155 (2006), p. 129.

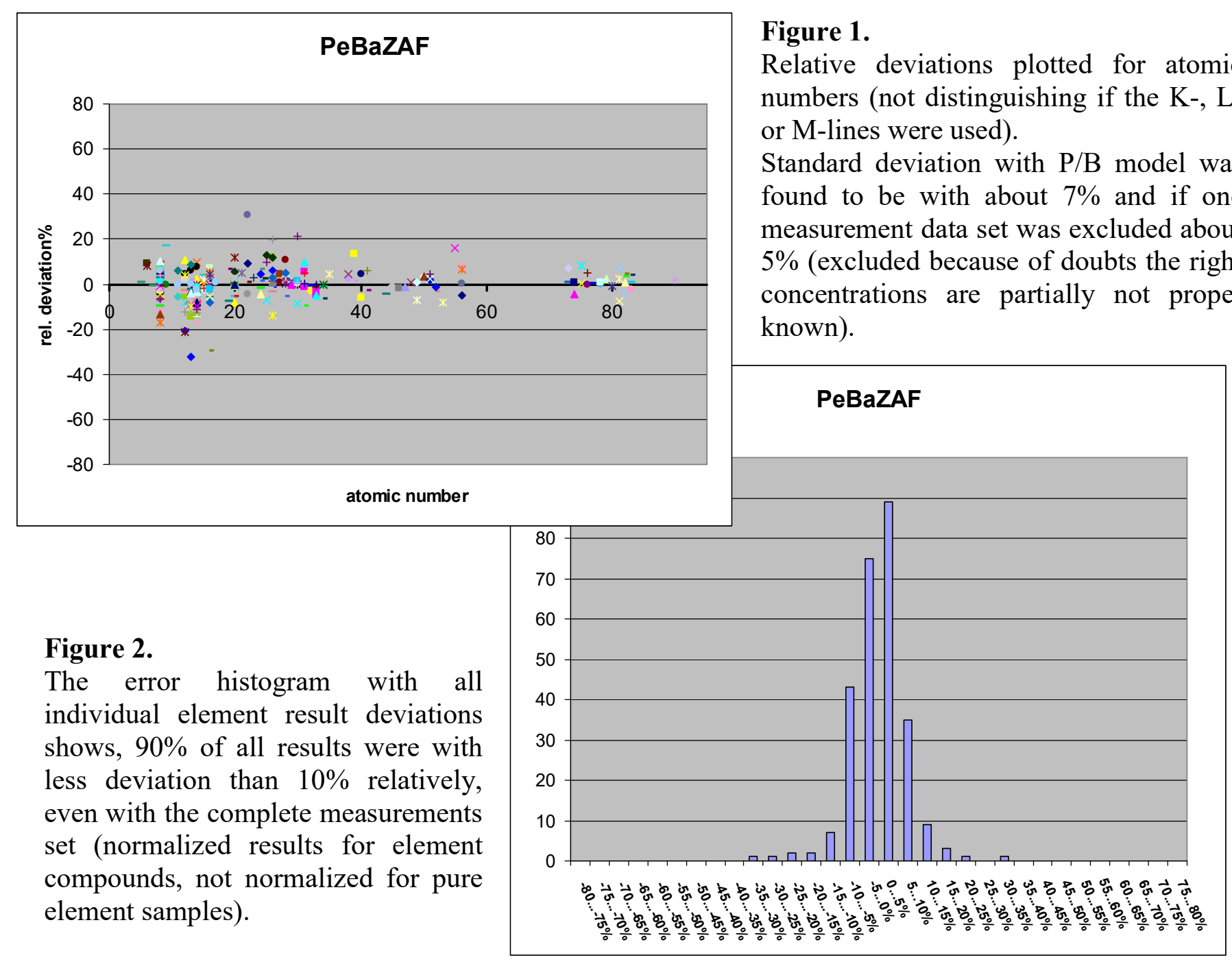

